\title{
Significance of Sublingual Gland Excision in Surgical Treatment of Ranula
}

\author{
Seok Hwa Ko, Hee Jeong Kang, Seon Min Jung, \\ Yong Bae Ji, Chang Myeon Song, and Kyung Tae \\ Department of Otorhinolaryngology-Head and Neck Surgery, Hanyang University College of Medicine, Seoul, Korea
}

\author{
하마종 수술에서 설하선 절제의 의의 \\ 고석화 · 강희정 · 정선민 · 지용배 · 송창면 · 태 경 \\ 한양대학교 의과대학 이비인후-두경부외과학교실
}

\author{
Received January 11, 2017 \\ Revised March 21, 2017 \\ Accepted March 24, 2017 \\ Address for correspondence \\ Kyung Tae, MD \\ Department of Otorhinolaryngology- \\ Head and Neck Surgery, \\ Hanyang University \\ College of Medicine, \\ 222 Wangsimni-ro, Seongdong-gu, \\ Seoul 04763, Korea \\ Tel $+82-2-2290-8585$ \\ Fax $+82-2-2293-3335$ \\ E-mail kytae@hanyang.ac.kr
}

Background and Objectives Ranulas, pseudo cysts found on the floor of mouth, develop from the retention or extravasation of saliva from the sublingual gland. The main treatment of ranula is surgical excision but the extent of surgery is controversial. The aim of this study was to evaluate the significance of sublingual gland excision in the surgical treatment of ranula. Subjects and Method We retrospectively reviewed 112 patients with ranula who had undergone surgical excision from January 2004 to April 2016. Those who underwent any previous treatment such as sclerotherapy, marsupialization, or excision of cyst were excluded in the study. Surgical outcomes including complications and recurrence were compared between the group that went through simple cyst excision and the group that went through cyst and sublingual gland excision.

Results Of 112 patients, 94 were simple ranula and 18 were plunging ranula. Thirty-seven $(33 \%)$ were male and 75 (67\%) were female. Of the 94 simple ranula patients, 23 underwent excision of cyst only; the remaining 71 patients and all other patients with plunging ranula underwent excision of cyst and sublingual gland together. The recurrence rate was significantly lower for the cyst and sublingual gland excision group than for the simple cyst excision group $(2.2 \%$ vs. $17.4 \%, p=0.004)$. The complication rate did not differ between the two groups $(4.3 \%$ vs. $1.1 \%$, $p=0.298$ ).

Conclusion The excision of sublingual glands as well as cysts is an important option to reduce recurrence in the surgical treatment of ranula.

Korean J Otorhinolaryngol-Head Neck Surg 2017;60(7):352-5

Key Words Complication - Ranula $\cdot$ Recurrence $\cdot$ Sublingual gland.

\begin{abstract}
서 론
하마종(ranula)은 구강저에 발생하는 점액 낭종으로 타액 선의 국소적 손상으로 인해 점액이 주위 연조직 내부에 저류 되어 생기는 가성 낭종이다. ${ }^{1,2)}$ 하마종은 구강저에 발생하며

This is an Open Access article distributed under the terms of the Creative Commons Attribution Non-Commercial License (http://creativecommons.org/licenses/by-nc/4.0) which permits unrestricted non-commercial use, distribution, and reproduction in any medium, provided the original work is properly cited.
\end{abstract}

종종 푸른빛을 띠어 ranula라고 명명되었는데, ${ }^{3)}$ 이는 낭종과 연부조직의 접점에서 푸른빛이 붉은빛보다 더 많이 반사되는 Tyndall effect 때문이다.)

크기는 다양하게 나타나며 크기가 큰 경우 연하 및 발음, 저 작 시 문제를 야기할 수 있다. ${ }^{1)}$ 발생 연령은 다양한 분포를 보 이나 청년층에서 많이 생기고, 여성에서 약간 더 호발한다. ${ }^{5)}$ 하 마종은 이환 범위에 따라 단순 하마종(simple ranula)과 몰입 성 하마종(plunging ranula)으로 나뉘며, ${ }^{6}$ 구강 내 낭성 종물 
로 나타나는 단순 하마종이 대부분을 차지하나 일부는 악설 골근 밑으로 침범되어 경부의 종물로 나타나는 몰입성 하마 종으로 나타난다. ${ }^{7)}$

하마종은 일반적으로 임상양상으로써 진단을 하게 되나, 초 음파, 컴퓨터전산화단층촬영, 자기공명영상촬영, 세침 흡인검 사 등이 이용되기도 한다. ${ }^{8,9)}$ 하마종의 치료로는 흡인술, 조대 술, 경화요법, 낭종 절제술, 낭종과 설하선 절제술 등이 있다. ${ }^{10)}$ 흡인술이나 조대술 등은 재발률이 높은 것으로 알려져 있으 나, 어떤 치료법이 가장 효과적인지 아직 확실히 정립된 근거 는 없는 실정이다.110) 하마종 치료 후 재발의 가능성을 낮추기 위해서는 하마종을 유발하는 설하선의 절제가 필요하다는 보고가 있으나, ${ }^{1,3)}$ 설하선 절제술을 시행하는 경우 혀의 감각 저하 또는 악하선관 손상 등의 합병증이 생길 수 있음을 주 의하여야 한다. ${ }^{11)}$ 본 연구에서는 하마종의 수술에 있어 설하 선 절제술의 시행 유무에 따른 재발률과 합병증 등의 임상양 상을 비교하여 설하선 절제의 의의에 대하여 알아보고자 하 였다.

\section{대상 및 방법}

본 연구에서는 2004년 1월에서 2016년 4월까지 하마종 절제 술 또는 하마종 절제술과 설하선 절제술을 동시에 시행받은 환자 112 명의 의무기록을 후향적으로 분석하였다. 하마종의 흡인술, 조대술 또는 경화요법을 시행하였거나 재발하여 재수

Table 1. Demographics of patient

\begin{tabular}{lc}
\hline \multicolumn{1}{c}{ Variable } & Number of patients $(\mathrm{n}=112)$ \\
\hline Gender (\%) & $37: 75(33: 67)$ \\
Male:female & $27 \pm 17$ \\
Age (mean \pm SD, years) & \\
Diagnosis (\%) & $94(83.9)$ \\
$\quad$ Simple ranula & $18(16.1)$ \\
Plunging ranula & \\
Extent of surgery (\%) & $23(20)$ \\
Simple cyst excision & $89(80)$ \\
Excision of cyst with & \\
sublingual gland & \\
\hline SD: standard deviation &
\end{tabular}

술을 시행한 경우는 본 연구에서 제외하였으며, 술 후 조직검 사상 구강저 이외의 단순 점액종이나 경부의 다른 병리소견의 낭종도 제외하였다. 연구 수행과 관련하여 임상시험심사위원 회(Institutional Review Board)의 심사면제 승인을 받았다.

수술은 국소마취 또는 전신마취를 시행하였으며, 전신마취 시에는 비강을 통한 비기도 삽관이 선호되었다. 단순 하마종의 경우 구강을 통해 낭종의 벽을 완전히 절제하는 낭종 절제술 을 시행하거나 낭종의 완전 절제와 함께 설하선 절제를 시행 하였다. 몰입성 하마종의 경우 구강 내 접근법을 통해 낭종의 아전절제를 시행하거나 경부로 내려간 낭종의 완전 절제를 위 해 구강과 경부 접근법을 같이 이용하였다.

환자의 나이 및 성별, 수술방법, 재발 및 합병증 등을 조사 하였으며, 낭종만 절제한 군과 낭종과 함께 설하선을 절제한 군으로 나누어 비교 분석하였다. 통계는 SPSS version 20.0 (SPSS Inc., Chicago, IL, USA)을 이용하여 Pearson's chisquare test 및 독립표본 $\mathrm{t}$ 검정을 이용하여 비교하였고, 통계 학적 유의 수준은 95\% 이상 $(p$-value<0.05)으로 하였다.

\section{결 과}

총 112예 중 남성이 37예, 여성이 75예로 여성이 약 2배가량

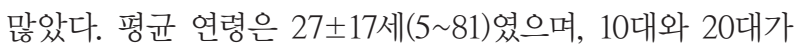
69예(61.6\%)로 가장 많았다. 총 112예 중 94예(83.9\%)는 단 순 하마종이었으며 나머지 18예(16.1\%)는 몰입형 하마종이었 다(Table 1).

수술의 범위는 23예(20\%)는 하마종 절제술만을 시행하였 으며 89예(79.5\%)에서는 하마종 절제술과 동시에 설하선 절 제술을 시행하였다. 수술 접근법은 단순 하마종의 경우 94예 모두 경구 접근법을 통해 시행하였으며, 18 예의 몰입형 하마 종의 경우 9예에서는 경구 접근법, 나머지 9예는 경구 접근법 과 경부 접근법을 함께 시행하여, 경부절개의 빈도는 두 군 간 에 유의한 차이를 보였다 $(p<0.001)$. 낭종과 함께 설하선을 절 제한 경우는 단순 하마종의 경우 $75.5 \%$ 에서 시행된 반면 몰 입형 하마종에서는 모든 예에서 설하선을 함께 절제하여 유 의한 차이를 보였다 $(p=0.019)$ (Table 2).

Table 2. Surgical approach and extent for ranula

\begin{tabular}{|c|c|c|c|}
\hline & Simple ranula $(n=94)$ & Plunging ranula $(n=18)$ & p-value \\
\hline Surgical approach (\%) & & & $<0.001$ \\
\hline Intraoral & $94(100)$ & $9(50)$ & \\
\hline Intraoral-transcervical & 0 & $9(50)$ & \\
\hline Extent of surgery (\%) & & & 0.019 \\
\hline Simple cyst excision & $23(24.5)$ & 0 & \\
\hline Excision of cyst with sublingual gland & $71(75.5)$ & $18(100)$ & \\
\hline
\end{tabular}


Korean J Otorhinolaryngol-Head Neck Surg I 2017;60(7):352-5

Table 3. Comparison of recurrence and complications in the surgical treatment of ranula

\begin{tabular}{lccc}
\hline \multicolumn{1}{c}{ Variable } & Simple cyst excision $(\mathrm{n}=23)$ & Excision of cyst and sublingual gland $(\mathrm{n}=89)$ & $\mathrm{p}$-value \\
\hline Follow-up period (month) & $4.43 \pm 11.88$ & $2.79 \pm 3.45$ & 0.52 \\
Recurrence (\%) & $4(17.4)$ & $2(2.2)$ & 0.004 \\
Complication (\%) & 0 & 0 & 0.298 \\
$\quad$ Hematoma & $1(4)$ & $1(1.1)$ & 0 \\
Tongue hypoesthesia & 0 & 0 & \\
Wound dehiscence & 0 & & \\
Marginal mandibular nerve palsy & & & \\
\hline
\end{tabular}

Table 4. Comparison of recurrence and complications in the surgical treatment of simple ranula with intraoral resection

\begin{tabular}{lccc}
\multicolumn{1}{c}{ Variable } & Simple cyst excision $(\mathrm{n}=23)$ & Excision of cyst and sublingual gland $(\mathrm{n}=71)$ & $\mathrm{p}$-value \\
\hline Recurrence $(\%)$ & $4(17.4)$ & $2(2.8)$ & 0.013 \\
Complication $(\%)$ & & & 0 \\
$\quad$ Hematoma & 0 & 0 & 0.077 \\
Tongue hypoesthesia & $1(4.3)$ & 0 & 0 \\
Wound dehiscence & 0 & 0 & \\
Marginal mandibular nerve palsy & 0 & & \\
\hline
\end{tabular}

수술 후 합병증은 낭종 절제술만 시행한 군과 낭종 절제와 설하선 절제술을 동시에 시행한 군 사이에 유의한 차이가 없었 으며 $(p=0.298)$, 양 군에서 혀의 감각저하를 호소한 경우가 각 1 예씩 있었으며, 악하선관 손상, 혈종, 수술부위 감염 등은 없 었다.

재발률은 단순 낭종 절제군에서는 23예 중 4예(17.4\%), 낭종 과 설하선 동시 절제술 군에서는 89예 중 2예(2.2\%)로 낭종 절 제술만 시행한 군에서 유의하게 높았다 $(p=0.004)$ (Table 3). 재 발한 경우는 두 군 모두에서 전부 단순 하마종이었으며, 모 든 예에서 설하선을 제거한 몰입형 하마종에서는 재발이 없 었다. 94예의 단순 하마종의 경우 재발은 단순 낭종 절제군 23예 중 4예(17.4\%), 낭종과 설하선 동시 절제군 71예 중 2예 (2.8\%)에서 발생하여 단순 낭종 절제군에서 유의하게 높았 다 $(p=0.013)$ (Table 4).

\section{고 찰}

하마종은 주로 설하선에서의 타액 유출로 인하여 발생한 다. 설하선은 다수의 Rivinus관 혹은 Batholin관을 통해 타 액을 구강저로 분비하거나 악하선관으로 분비한다. Batholin 관이 악하선관으로 분비되는 경우 악하선의 타액 분비에 의 한 생리학적 폐쇄 및 역류로 설하선내의 소포에 파열을 야기 할 수 있다. ${ }^{12)}$ 반면에 악하선은 보다 단단한 막에 싸여 있기에 파열에 의한 타액의 유출이 드물다. 또한 설하선은 악하선보 다 점성이 높은 타액을 소화와 관계없이 지속적으로 분비하 기에 저류가 잘 일어난다. ${ }^{13)}$

하마종의 치료는 흡인술, 경화요법, 조대술, 낭종 절개, 낭
종 절제, 설하선 절제술 등 다양한 방법이 제시되고 있다. ${ }^{14,15)}$ 흡인술은 매우 간편하여 소아환자 등에서 선택적으로 시행될 수 있는데, 3 개월 이하의 유아에서 시행한 결과 $82 \%$ 의 높은 재발률이 보고되었다. ${ }^{16)}$ 경화요법도 사용되고 있는데, $\mathrm{OK}-432$ 를 이용한 경화요법에 대한 한 논문을 보면 총 32예의 $75 \%$ 에서 완전 관해를 보였으나, 평균 2차례 이상의 시술이 필요 하였으며 9\%에서는 전혀 반응이 없었다고 보고하였다. ${ }^{17)}$ 조 대술은 술식의 간편함으로 인해 낭종 절제술 대신 시행하는 경우가 있으나 재발률이 상대적으로 높아 14 67\%로 다양하 게 보고되며, 2,8,18) 낭종의 단순절제술 역시 재발률이 12 58\% 로 다양하다. 그러나 하마종과 함께 설하선을 같이 절제한 경우는 상대적으로 재발률이 낮게 보고되었다. ${ }^{2,3,10,19)}$

27예의 하마종을 대상으로 분석한 이전의 한 연구를 보면 초기 치료로 조대술, 단순 낭종 절제술, 낭종 절제술과 설하선 절제술을 동시에 시행한 경우를 비교하였는데, 재발률이 각각 $38,25,0 \%$ 라고 보고하였다. ${ }^{18)} 580$ 예의 하마종에 대하여 술 식에 따른 재발률을 분석한 다른 연구에서는 낭종의 단순절 제를 시행한 경우 26예 중 15예(58\%)에서 재발한 반면, 설하선 절제술만 시행한 경우 286예 중 3예(1\%), 설하선 절제와 낭종 절제술을 동시에 시행한 경우 129예 중 2예(2\%)에서만 재발 하여 낭종 절제만 시행한 경우에 비하여 설하선을 제거한 경 우가 통계적으로 유의하게 재발률이 낮다고 보고하였다. ${ }^{2)} 83$ 예의 수술적 치료를 받은 하마종에 대한 또 다른 연구에서 조 대술을 시행한 경우 $20 \%$ 에서 재발이 있었으나, 설하선과 하 마종을 절제한 경우는 재발이 없었다고 보고되었다. ${ }^{19)}$ 총 22 예의 몰입형 하마종의 치료결과에 대한 연구에서는 단순 낭 종 절제술을 시행한 경우 $63 \%$ 에서 재발하였으나, 설하선 절제 
술과 낭종 절제술을 같이 시행하였던 경우 재발이 없었다고 보 고하였다. ${ }^{3)}$

이와 같은 연구들은 하마종의 발생 근거가 되는 설하선을 절제하는 것이 수술 후의 재발률을 낮출 수 있다는 것을 시사 하며, $2,7,9,20)$ 본 연구에서도 낭종의 단순절제를 시행한 군에서 는 23 예 중 4 예에서 재발하여 $17.4 \%$ 의 재발률을 보인 반면 설 하선을 함께 절제한 경우는 89 예 중 2예에서 재발하여 $2.2 \%$ 로 통계적으로 유의하게 낮은 재발률을 보였다. 특히 본 연구 에 포함된 18 예의 몰입형 하마종의 경우, 가성 낭종벽의 완전 절제가 구강접근법만으로는 어렵기 때문에 낭종의 완전 절 제와 설하선의 절제를 위하여 9예에서는 경부 및 구강 접근 법을 같이 이용하였으며, 나머지 9예는 구강접근법만으로 설 하선 절제와 경부로 내려간 낭종의 아전절제를 시행하였는 데, 모든 예에서 재발은 관찰되지 않았다. 이는 하마종의 수 술에서 가성 낭종의 완전 절제보다는 설하선의 절제가 더 중 요한 인자임을 시사하는 소견으로 사료된다. 864예의 하마 종을 분석한 한 연구에서 몰입형 하마종에서 설하선만을 절 제한 경우와 경부접근으로 낭종의 완전 절제를 함께 시행한 경우 모두 재발이 없었다고 보고하였으며, ${ }^{10)}$ 재발한 하마종의 수술에 관한 연구에서도 설하선만 절제한 경우 286예 중 3예 (1.05\%), 하마종과 설하선 절제를 동시에 시행한 경우 129예 중 2예(1.55\%)에서 재발하여 유의한 차이가 없었다. ${ }^{11)}$

하마종의 수술 중 발생할 수 있는 합병증은 설신경 손상에 따른 혀의 감각저하와 악하선관의 손상이 가장 흔하며, 합병 증 빈도와 수술 범위와의 연관성에는 논란이 있다. 606예의 하마종 수술결과를 분석한 연구에서 악하선관 손상은 $2 \%$ 에 서, 혀의 감각저하는 $5 \%$ 에서 발생하였으며, 수술범위에 따라 분석하면 설하선을 함께 절제한 경우에서 혀의 감각저하 발 생률이 $12 \%$ 로 낭종 절제술만 시행한 경우의 발생률인 $4 \%$ 보 다 높다고 보고하였다. 악하선관의 손상 또한 하마종과 설하 선을 함께 절제한 경우에는 $3 \%$ 로 낭종 절제술만 시행하였을 때는 악하선관의 손상이 보고되지 않은 것과 비교할 때 높았 다. ${ }^{11)}$ 그러나 864 예의 하마종을 분석한 다른 연구에서는 혀 의 감각저하가 설하선과 하마종을 함께 절제한 경우와 낭종 의 단순절제한 경우 모두 $8 \%$ 로 차이가 없었다. 또한 악하선 관의 손상도 설하선과 하마종을 함께 절제한 경우 $(0.3 \%)$ 와 낭종의 단순절제만 시행한 경우( $0 \%)$ 에 유의한 차이가 없었 다. ${ }^{10)}$ 본 연구에서도 하마종 수술 후 합병증 발생 빈도는 약 $2 \%$ 로 비교적 낮았으며, 하마종 단순절제군과 설하선을 함께 절제한 군 간에 합병증 발생의 유의한 차이는 없었다. 술 중 설 신경이나 악하선관을 주의 깊게 확인하여 보존하는 것이 합병 증을 예방하는 데 필요하리라 생각된다.

이상의 결과로 하마종의 수술 시 낭종 절제술과 더불어 설
하선을 함께 절제하는 것이 재발률을 낮출 수 있는 효과적인 방법이며, 술자가 충분히 주의를 기울인다면 설하선 절제에 따른 합병증도 낭종의 단순절제와 차이를 보이지 않는다고 사 료된다.

\section{REFERENCES}

1) Kim BH, Ryu YJ, Jung YH. Pathophysiology and management of the ranula. Korean J Otorhinolaryngol-Head Neck Surg 2016;59(5): 339-45.

2) Zhao YF, Jia Y, Chen XM, Zhang WF. Clinical review of 580 ranulas. Oral Surg Oral Med Oral Pathol Oral Radiol Endod 2004;98(3): 281-7.

3) Lee HM, Lee JH, Cho JG, Song JS, Lee SH, Woo JS, et al. Clinical analysis of the 22 cases of plunging ranula. Korean J OtorhinolaryngolHead Neck Surg 2003;46(9):764-8.

4) McGurk M, Eyeson J, Thomas B, Harrison JD. Conservative treatment of oral ranula by excision with minimal excision of the sublingual gland: histological support for a traumatic etiology. J Oral Maxillofac Surg 2008;66(10):2050-7.

5) Langlois NE, Kolhe P. Plunging ranula: a case report and a literature review. Hum Pathol 1992;23(11):1306-8.

6) Huang SF, Liao CT, Chin SC, Chen IH. Transoral approach for plunging ranula--10-year experience. Laryngoscope 2010;120(1):53-7.

7) Hong KH, Yang YS, Park HT, Hwang BE, Lee KS, Lim SH, et al. Surgical results of the intraoral removal for plunging ranula. Korean J Otorhinolaryngol-Head Neck Surg 2010;53(11):702-5.

8) Sigismund PE, Bozzato A, Schumann M, Koch M, Iro H, Zenk J. Management of ranula: 9 years' clinical experience in pediatric and adult patients. J Oral Maxillofac Surg 2013;71(3):538-44.

9) Lee DH, Yoon TM, Lee JK, Lim SC. Treatment outcomes of the intraoral approach for a simple ranula. Oral Surg Oral Med Oral Pathol Oral Radiol 2015;119(4):e223-5.

10) Patel MR, Deal AM, Shockley WW. Oral and plunging ranulas: what is the most effective treatment? Laryngoscope 2009;119(8):1501-9.

11) Zhao YF, Jia J, Jia Y. Complications associated with surgical management of ranulas. J Oral Maxillofac Surg 2005;63(1):51-4.

12) Zhang B, Yang Z, Zhang RM, Liu L, Zhang F, Chen J, et al. Are the patients with anatomic variation of the sublingual/Wharton's duct system predisposed to ranula formation? Int J Pediatr Otorhinolaryngol 2016;83:69-73.

13) Chen CJ, Guo P, Chen XY. Recurrent sublingual ranula or saliva leakage from the submandibular gland? Anatomical consideration of the ductal system of the sublingual gland. J Oral Maxillofac Surg 2015;73(4):675.e1-7.

14) Morita Y, Sato K, Kawana M, Takahasi S, Ikarashi F. Treatment of ranula--excision of the sublingual gland versus marsupialization. Auris Nasus Larynx 2003;30(3):311-4.

15) Zola M, Rosenberg D, Anakwa K. Treatment of a ranula using an Er, Cr: YSGG laser. J Oral Maxillofac Surg 2006;64(5):823-7.

16) Zhi K, Wen Y, Ren W, Zhang Y. Management of infant ranula. Int J Pediatr Otorhinolaryngol 2008;72(6):823-6.

17) Kim HS, Roh JL. Sclerotherapy of ranula with intracystic injection of OK-432. Korean J Otorhinolaryngol-Head Neck Surg 2006;49(10): 1003-7.

18) Yoshimura $Y$, Obara $S$, Kondoh T, Naitoh S. A comparison of three methods used for treatment of ranula. J Oral Maxillofac Surg 1995; 53(3):280-2; discussion 283.

19) Chidzonga MM, Mahomva L. Ranula: experience with 83 cases in Zimbabwe. J Oral Maxillofac Surg 2007;65(1):79-82.

20) Yoo BY, Yoo JK, Kim DK, Lee EJ, Park JS. Intraoral approach in plunging ranula. Korean J Otolaryngol-Head Neck Surg 2005;48(4): $516-9$. 